\title{
Heart rate response during vasodilator stress myocardial perfusion imaging: Mechanisms and implications
}

\author{
Fadi G. Hage, $M D,{ }^{a, b}$ and Ami E. Iskandrian, MD, MACC
}

\section{See related article, pp. 617-624}

Myocardial perfusion imaging (MPI) using adenosine, dipyridamole, or regadenoson (a selective $\mathrm{A}_{2 \mathrm{~A}}$ receptor agonist) is an established method for detecting coronary artery disease (CAD) and risk stratification. ${ }^{1}$ In high-risk populations, as in those with diabetes mellitus (DM) or chronic kidney disease, MPI has been shown to be a powerful predictor of risk, but nevertheless, patients with normal myocardial perfusion are at higher risk than those without DM or chronic kidney disease. ${ }^{2,3}$ Thus, there continues to be a need to extract more useful prognostic data from stress MPI especially in high-risk populations.

A blunted heart rate $(\mathrm{HR})$ response to exercise stress has been known to be an independent predictor of poor outcome and is used clinically in conjunction with other prognostic variables such as perfusion defects, left ventricular (LV) ejection fraction $(\mathrm{EF})$ and volumes, exercise time, and symptoms during exercise to derive an overall assessment of risk in a particular patient. ${ }^{4}$ In patients undergoing stress testing, for one reason or another, with adenosine or regadenoson (and dipyridamole, which acts indirectly by increasing interstitial levels of endogenous adenosine), there is a modest increase in HR and a modest decrease in blood pressure (BP). The increase in HR has been traditionally attributed to a reflex response to the vasodilatory effect on the systemic circulation and the resultant increase in

From the Division of Cardiovascular Diseases, ${ }^{\text {a }}$ University of Alabama at Birmingham, Birmingham, AL; Section of Cardiology, ${ }^{\mathrm{b}}$ Birmingham Veteran's Administration Medical Center, Birmingham, AL.

Reprint requests: Fadi G. Hage, MD, Division of Cardiovascular Diseases, University of Alabama at Birmingham, Zeigler Research Building 1024, 1530 3rd AVE S, Birmingham, AL 35294-0006; fadihage@uab.edu.

J Nucl Cardiol 2010;17:536-9.

$1071-3581 / \$ 34.00$

Copyright $(2010$ by the American Society of Nuclear Cardiology. doi:10.1007/s12350-010-9248-9 sympathetic discharge. ${ }^{5,6}$ The true mechanism of HR increase, however, is more complicated and involves direct stimulation of the sympathetic nervous system. ${ }^{7}$ The administration of adenosine as a bolus, as done for the interruption of supra-ventricular tachycardias, has a negative chronotropic effect on the atrio-ventricular node via stimulation of the A1 receptor. This is in contradistinction to its effect on the $\mathrm{A}_{2 \mathrm{~A}}$ receptor when given as an infusion in stress MPI studies where it induces an increase in HR. ${ }^{5,8}$ The development of selective $A_{2 \mathrm{~A}}$ receptor agonists (such as regadenoson) has allowed for the dissection of the effects of adenosine on the multiple receptors. A well-done pivotal study in rats by Dhalla et $\mathrm{al}^{7}$ that used regadenoson in combination with a selective $\mathrm{A}_{2 \mathrm{~A}}$ receptor antagonist, B-blocker, a ganglionic blocker (to block the sympathetic nervous system), and a direct vasodilator (nitroprusside) demonstrated the dissociation of tachycardia and hypotension (secondary to peripheral vasodilation) responses to regadenoson. This and other data (reviewed in Ref. ${ }^{9}$ ) confirm that $\mathrm{A}_{2 \mathrm{~A}}$ receptor agonists cause a direct stimulation of the autonomic nervous system, which results in sinus tachycardia independent of the baroreflex mechanism. Thus, the change in $\mathrm{HR}$ in response to $\mathrm{A}_{2 \mathrm{~A}}$ receptor agonists can be used to evaluate autonomic function.

In order to evaluate the HR response to adenosine and regadenoson in relation to DM (since there is a high prevalence of autonomic dysfunction in patients with DM), we used data from the ADenoscan Versus RegAdenosoN Comparative Evaluation for Myocardial Perfusion Imaging (ADVANCE MPI 1 and 2) Trials.9, ${ }^{9,10}$ The ADVANCE MPI Trials ${ }^{11,12}$ are randomized multicenter phase 3 trials that demonstrated the noninferiority of regadenoson to adenosine in detecting reversible defects by comparing the strength of agreement between sequential adenosine-regadenoson and adenosine-adenosine images. The $\mathrm{HR}$ and BP were measured at baseline and at predetermined intervals extending to 45 minutes after the administration of adenosine or regadenoson. In the 2,000 patients with known DM status (643 with DM, 1357 non-DM, 15 unknown DM status) there was a blunted HR response (maximal percent change of HR from baseline) in those 
with DM $(29.42 \pm .64$ vs $36.08 \pm .54 \%, P<.001) .{ }^{9}$ A larger proportion of patients with a HR response in the lower vs upper tertile had DM $(40 \%$ vs $22 \%, P<.001)$. This relationship was present irrespective of age, gender, myocardial perfusion abnormalities, LV function, use of beta-blockers, and renal function, and was dissociated from the BP response. ${ }^{9}$ Similarly, patients with the metabolic syndrome had a lower HR response than those without it $(32.43 \pm .52$ vs $36.15 \pm .71 \%, P<.001)$, and there was a stepwise decrease in the HR response for increasing features of the metabolic syndrome and for increasing blood sugar levels on the morning of the MPI even in patients not known to have DM (Figure 1). ${ }^{10}$ Decreasing renal function was also linearly related to decreasing HR response (Figure 2). In a multivariate model, DM status, metabolic syndrome status and renal function were all independently associated with the HR response after controlling for age, gender, LV function, BP, baseline $\mathrm{HR}$, and beta-blocker use. ${ }^{10}$ Although these associations were similar irrespective of whether patients received adenosine or regadenoson, the HR increased to a greater extent with regadenoson than with adenosine. Thus, non-DM patients had a $31 \%$ increase in their HR with adenosine compared to $39 \%$ with regadenoson and the corresponding numbers for DM patients were $26 \%$ and $31 \%$.

In the study by Mathur et al reported in this issue of the Journal ${ }^{13}$ an increase in HR by less than $20 \%$ in response to dipyridamole was considered blunted, and this was present in $64 \%$ of the entire population $(2,890$ out of 4,484 patients). Therefore, caution must be

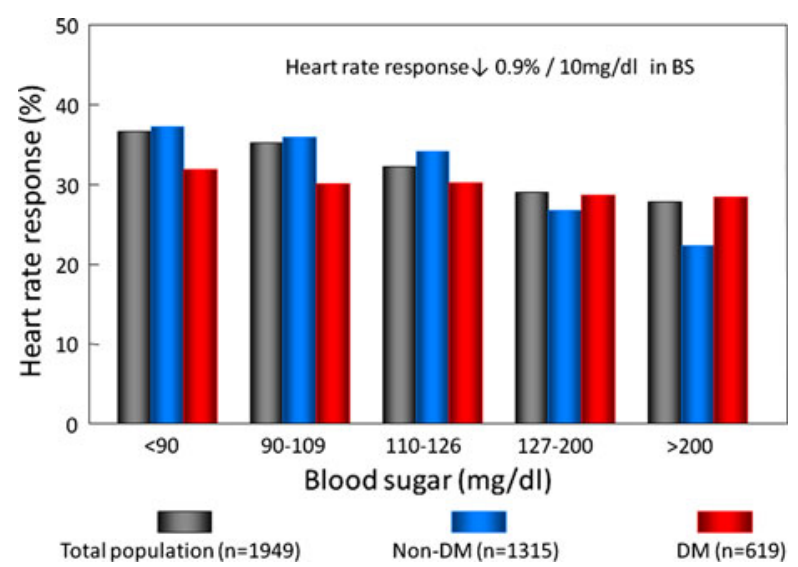

Figure 1. The heart rate response to adenosine or regadenoson in the ADVANCE MPI trials in patients according to their blood sugar level on the day of the vasodilator stress myocardial perfusion imaging. There is a stepwise decrease in the heart rate response with increasing blood sugar levels both in patients with diabetes mellitus (DM) and in those without DM (non-DM) $(P<.001)$. Figure modified from Ref. ${ }^{10}$

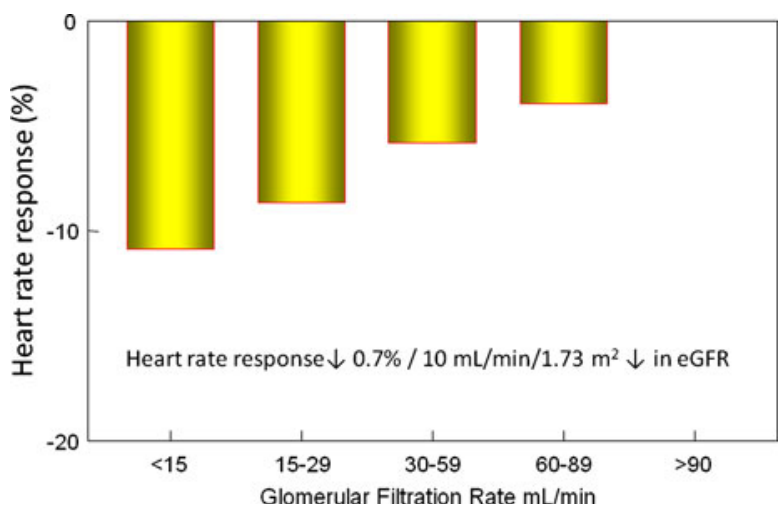

Figure 2. There is a stepwise association between the heart rate response to adenosine or regadenoson in relation to decreasing estimated glomerular filtration rate. The heart rate response for each category of renal function is compared to the reference value of patients with estimated glomerular filtration rate $>90$, who had an average heart rate response of $38.1 \%$. Figure based on data from Ref. ${ }^{9}$

exercised in the utilization of data from these multiple agents since they have different pharmacokinetic properties although they all act by stimulating the adenosine receptors. Further studies are definitely needed to characterize ideal cutoffs tailored for each reagent.

Since cardiac autonomic dysfunction has been linked to increased cardiovascular risk, ${ }^{14}$ the evaluation of the HR response to these vasodilators can be prognostically useful. The relation between autonomic dysfunction and outcome is supposedly due to an increase in sudden death due to arrhythmias. Imaging using I-123 metaiodobenzylguanidine (MIBG), a nonmetabolized norepinephrine analogue, has been used to aid in the diagnosis of cardiac autonomic denervation and has been shown to be prognostically useful in DM and heart failure patients. ${ }^{15,16}$ Indeed, in dogs, the induction of sustained ventricular tachycardia after myocardial infarction has been shown to be associated with a larger area of myocardial perfusion-innervation mismatch as assessed by [13N]-ammonia and [11C]epinephrine positron emission tomography. ${ }^{17}$ Abidov et al were the first to report on the prognostic significance of the HR change after adenosine infusion. ${ }^{18}$ In their study, the hemodynamic response of 3,444 patients who underwent adenosine MPI was assessed. After $2.0 \pm .8$ years, $6.5 \%$ of the population experienced cardiac death, and a blunted HR response (defined as low peak/rest HR) was an independent predictor of poor outcome after controlling for clinical and perfusion variables. The size of the perfusion abnormality (summed stress score) and the HR response added incremental prognostic information for the prediction of cardiac deaths. ${ }^{18}$ In another study, a low HR response to dipyridamole has been associated with all-cause 
mortality in 1,087 patients with normal myocardial perfusion followed for 8 years even after adjustment for multiple factors. ${ }^{19}$ Since sudden cardiac death is a major cause of mortality in end-stage renal disease (ESRD), ${ }^{20}$ and the HR response to adenosine showed a strong relationship to renal function, ${ }^{9,10}$ we examined the prognostic significance of this parameter in ESRD patients. ${ }^{21}$ In a well characterized cohort of ESRD patients awaiting renal transplantation who underwent screening adenosine MPI followed by invasive coronary angiography, the HR response was lower than a control population and a blunted HR response in this population was a strong independent predictor of death ${ }^{21}$ (Figure 3). This association was independent of LVEF, presence and extent of CAD by angiography and size of perfusion abnormality by MPI. A blunted HR response in this study was a stronger predictor of all-cause mortality than perfusion abnormalities by MPI or angiographic presence of CAD. $^{21}$

The study by Mathur et al adds to an expanding body of evidence that suggests that HR response to vasodilators is just as important as HR response during exercise and should be included in future studies of risk assessment. Ideally, the role of blunted HR response in predicting sudden death rather than all-cause mortality or composite end points should be studied, although the adjudication of whether death is sudden or non-sudden is

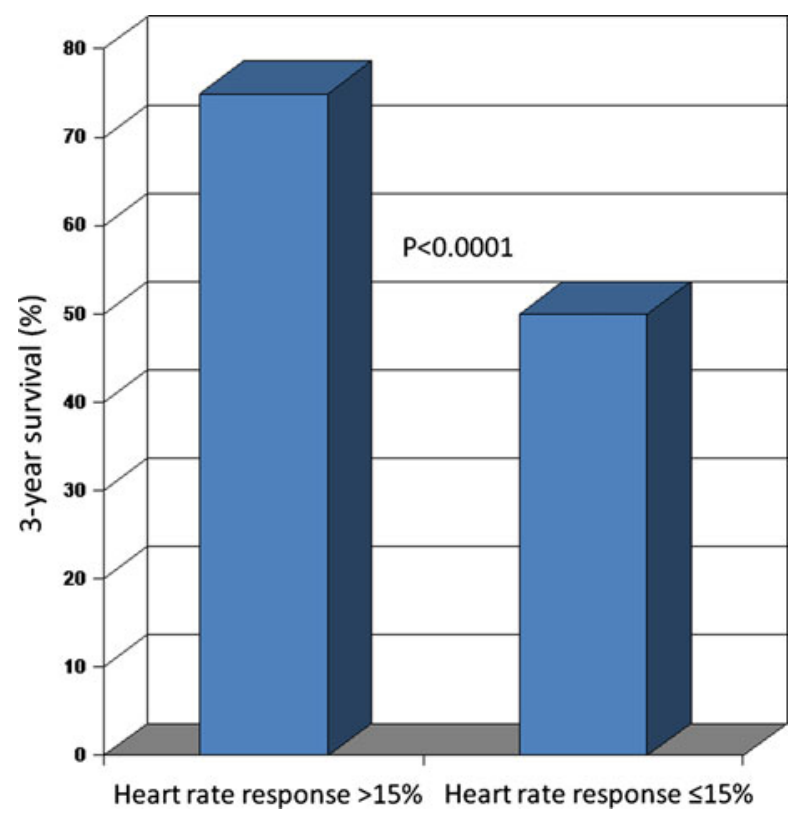

Figure 3. Survival at 3-years is significantly lower in patients with end-stage renal disease with a blunted heart rate response to adenosine (\% change in heart rate $\leq 15 \%$ ) as compared to those with higher heart rate response. Figure based on data from Ref. ${ }^{21}$ even more difficult than whether death is cardiac or noncardiac. The Duke investigators have examined the predictors of sudden death using the largest database available and have carefully crafted the criteria of defining sudden death. ${ }^{22,23}$

Impressively, a blunted HR response to dipyridamole in the Mathur study was independently associated with increased cardiac death even after controlling for myocardial perfusion, LVEF, age, abnormal electrocardiogram and a history of DM, myocardial infarction, and heart failure. The HR response was thus predictive of cardiac death in subgroups of patients with low, intermediate, and high summed stress score and whether or not patients were receiving beta-blocker therapy. As pointed out in their article, and as anticipated based on the data from ADVANCE MPI, more patients with DM had a blunted HR response to dipyridamole. The authors correctly point out that a blunted HR response is prognostically useful in diabetics and that DM patients with a blunted HR response had a higher event rate than nonDM patients with a blunted response. Interestingly, however, a blunted HR response predicted cardiac death just as well in non-DM patients and patients without DM with a blunted HR response had an annualized cardiac death rate of $>3 \%$, which is numerically higher than DM patients with a higher HR response. Future studies should examine the relationship between HR response and other direct measures of autonomic function including the perfusion-denervation mismatch pattern. It remains to be determined whether the HR response could be modified by life style changes or medications and whether such a modification results in a directional change in patient outcome. Finally, the relationship of HR response as a continuum and outcome and the particular cutoff point in an individual patient that defines a poor outcome need to be defined.

\section{Acknowledgement}

AEI is consultant to Gilead and received research grants from Gilead and Astellas Pharm, USA.

\section{References}

1. Iskandrian AE, Garcia EV. Nuclear cardiac imaging: Principles and applications. Oxford: Oxford University Press; 2008.

2. Hakeem A, Bhatti S, Dillie KS, Cook JR, Samad Z, Roth-Cline $\mathrm{MD}$, et al. Predictive value of myocardial perfusion single-photon emission computed tomography and the impact of renal function on cardiac death. Circulation 2008;118:2540-9.

3. Giri S, Shaw LJ, Murthy DR, Travin MI, Miller DD, Hachamovitch R, et al. Impact of diabetes on the risk stratification using stress single-photon emission computed tomography myocardial perfusion imaging in patients with symptoms suggestive of coronary artery disease. Circulation 2002;105:32-40. 
4. Lauer MS, Francis GS, Okin PM, Pashkow FJ, Snader CE, Marwick TH. Impaired chronotropic response to exercise stress testing as a predictor of mortality. Jama 1999;281:524-9.

5. Clarke B, Conradson TB, Dixon CM, Barnes PJ. Reproducibility of heart rate changes following adenosine infusion in man. Eur J Clin Pharmacol 1988;35:309-11.

6. Alberti C, Monopoli A, Casati C, Forlani A, Sala C, Nador B, et al. Mechanism and pressor relevance of the short-term cardiovascular and renin excitatory actions of the selective A2A-adenosine receptor agonists. J Cardiovasc Pharmacol 1997;30:320-4.

7. Dhalla AK, Wong MY, Wang WQ, Biaggioni I, Belardinelli L. Tachycardia caused by A2A adenosine receptor agonists is mediated by direct sympathoexcitation in awake rats. J Pharmacol Exp Ther 2006;316:695-702.

8. Johnston DL, Daley JR, Hodge DO, Hopfenspirger MR, Gibbons RJ. Hemodynamic responses and adverse effects associated with adenosine and dipyridamole pharmacologic stress testing: A comparison in 2,000 patients. Mayo Clin Proc 1995;70:331-6.

9. Hage FG, Heo J, Franks B, Belardinelli L, Blackburn B, Wang W, et al. Differences in heart rate response to adenosine and regadenoson in patients with and without diabetes mellitus. Am Heart J 2009; 157:771-6.

10. Hage FG, Perry G, Heo J, Iskandrian AE. Blunting of the heart rate response to adenosine and regadenoson in relation to hyperglycemia and the metabolic syndrome. Am J Cardiol 2010;105: 839-43.

11. Iskandrian $\mathrm{AE}$, Bateman $\mathrm{TM}$, Belardinelli L, Blackburn B, Cerqueira MD, Hendel RC, et al. Adenosine versus regadenoson comparative evaluation in myocardial perfusion imaging: Results of the ADVANCE phase 3 multicenter international trial. J Nucl Cardiol 2007; 14:645-58.

12. Cerqueira MD, Nguyen $P$, Staehr P, Underwood SR, Iskandrian AE. Effects of age, gender, obesity, and diabetes on the efficacy and safety of the selective A2A agonist regadenoson versus adenosine in myocardial perfusion imaging: Integrated ADVANCEMPI trial results. J Am Coll Cardiol Cardiol Img 2008;1:307-16.

13. Mathur S, Shah AR, Ahlberg AW, Katten DM, Heller GV. Blunted heart rate response as a predictor of cardiac death in patients undergoing vasodilator stress technetium-99m sestamibi gated SPECT myocardial perfusion imaging. J Nucl Cardiol 2010. doi:10.1007/s12350-010-9242-2.

14. Maser RE, Mitchell BD, Vinik AI, Freeman R. The association between cardiovascular autonomic neuropathy and mortality in individuals with diabetes: A meta-analysis. Diabetes Care 2003;26:1895-901.

15. Nagamachi S, Fujita S, Nishii R, Futami S, Tamura S, Mizuta M, et al. Prognostic value of cardiac I-123 metaiodobenzylguanidine imaging in patients with non-insulin-dependent diabetes mellitus. J Nucl Cardiol 2006;13:34-42.

16. Jacobson AF, Senior R, Cerqueira MD, Wong ND, Thomas GS, Lopez VA, et al. Myocardial Iodine-123 meta-iodobenzylguanidine imaging and cardiac events in heart failure results of the prospective ADMIRE-HF (AdreView myocardial imaging for risk evaluation in heart failure) Study. J Am Coll Cardiol 2010;55: 2212-21.

17. Sasano T, Abraham MR, Chang KC, Ashikaga H, Mills KJ, Holt $\mathrm{DP}$, et al. Abnormal sympathetic innervation of viable myocardium and the substrate of ventricular tachycardia after myocardial infarction. J Am Coll Cardiol 2008;51:2266-75.

18. Abidov A, Hachamovitch R, Hayes SW, Ng CK, Cohen I, Friedman JD, et al. Prognostic impact of hemodynamic response to adenosine in patients older than age 55 years undergoing vasodilator stress myocardial perfusion study. Circulation 2003; 107:2894-9.

19. Bhatheja R, Francis GS, Pothier CE, Lauer MS. Heart rate response during dipyridamole stress as a predictor of mortality in patients with normal myocardial perfusion and normal electrocardiograms. Am J Cardiol 2005;95:1159-64.

20. Hage FG, Venkataraman R, Zoghbi GJ, Perry GJ, DeMattos AM, Iskandrian AE. The scope of coronary heart disease in patients with chronic kidney disease. J Am Coll Cardiol 2009;53:2129-40.

21. Venkataraman R, Hage FG, Dorfman TA, Heo J, Aqel RA, de Mattos AM, et al. Relation between heart rate response to adenosine and mortality in patients with end-stage renal disease. Am J Cardiol 2009;103:1159-64.

22. Piccini JP, Horton JR, Shaw LK, Al-Khatib SM, Lee KL, Iskandrian AE, et al. Single-photon emission computed tomography myocardial perfusion defects are associated with an increased risk of all-cause death, cardiovascular death, and sudden cardiac death. Circ Cardiovasc Imaging 2008;1:180-8.

23. Piccini JP, Aijing Z, Starr AZ, Horton JR, Shaw LK, Lee KL, et al. SPECT myocardial perfusion imaging and the risk of sudden cardiac death in patients with coronary disease and left ventricular ejection fraction $>35 \%$. J Am Coll Cardiol 2010 (in press). 